\title{
PERFILES DEL LECTOR UNIVERSITARIO: GUSTO, IMPORTANCIA Y VIVENCIA DE LA LITERATURA
}

\author{
UNIVERSITY READER PROFILES: \\ ENJOYMENT, IMPORTANCE AND \\ EXPERIENCE OF LITERATURE
}

doi: 10.21555/ rpp.v33i33.2395

Fabiola Torres Adame

Universidad Anáhuac México, México

fabiola.torresa@anahuac.mx

https:// orcid.org/0000-0002-2557-4401

Recibido: septiembre 17, 2021 - Aceptado: octubre 18, 2021

\section{RESUMEN}

En lo que respecta a la práctica de la lectura, es importante enfocarse no solo en cuánto se lee, sino en qué se lee y para qué; si los textos leídos inciden en el proceso de humanización del hombre. La obra literaria es fuente potencial de formación integral, pues da cuenta de la cultura y la condición humana. En el contexto universitario, y a fin de implementar exitosamente actividades promotoras de la lectura, es clave conocer el perfil lector literario de los estudiantes, esto es: qué tanto les gusta y leen literatura, qué importancia conceden a la lectura de obras literarias, con qué frecuencia la hacen vida y en qué medida les gustaría participar en determinadas actividades promotoras de la lectura de obras literarias, si se ofrecieran en su universidad. Con este objetivo, se realizó un estudio cuantitativo con una muestra de 1,111 estudiantes de primer semestre en una universidad privada en México, a través del diseño y aplicación de una encuesta tipo Likert. El análisis de conglomerados jerárquicos arroja como resultado tres niveles de perfil lector literario: bajo, medio y alto, de acuerdo con la disposición de los estudiantes ante la literatura. En general, se concluye que es importante enfatizar la enseñanza sobre el poder transformador de la literatura y que las experiencias de lectura inviten a la vivencia del texto.

Palabras clave: cultura y humanización, perfil del lector, importancia de la literatura, vivir la literatura, promoción de la lectura, universitarios. 


\section{ABSTRACT}

When reading, it is important to focus not only on how much of it is done, but on what is read and why; and think about whether the texts that have been read affect the humanisation process. Literature is a potential source of comprehensive education or integral development, since it encapsulates the culture and human condition. In the university context and in order to successfully implement activities that promote reading, it is essential to know the literary reading profile of students: how much they like and do read literature, the importance they give to reading literary works, how often they bring it to life and the extent in which they agree to participate in certain activities that promote the reading of literary works (if those are offered at their university). A quantitative study was conducted with a sample of 1,111 first semester students at a Private University in Mexico, through the design and application of a Likert-type survey. Hierarchical cluster analysis yields as a result three levels of literary reading profile according to the disposition of the students towards literature: low, medium and high. In general, it is important to implement activities that emphasize the transforming effect of literature and invite students to bring reading alive.

Keywords: Culture and Humanization, Reader Profile, Literature Value, Bring Literature Alive, Reading Promotion, University Students.

\section{INTRODUCCIÓN}

De acuerdo con la Declaración de México sobre las Políticas Culturales (UNESCO, 1982), la educación y la cultura son esenciales para el desarrollo del individuo y de la sociedad, y este desarrollo va de la mano de la capacidad de las personas para informarse, aprender y comunicar sus experiencias. Para ello, la lectoescritura es uno de los medios por excelencia (Goodman, 2015; Reyes, 1997). En lo que respecta a la práctica de la lectura en México, los resultados del Módulo de Lectura (MOLEC) (INEGI, 2020), dirigido a la población alfabeta de 18 y más años de edad, señalan que el $72.4 \%$ lee algún tipo de material (libros, revistas, periódicos, historietas y páginas de internet, foros o blogs), y que los lectores de libros prefieren literatura $(42.3 \%)$ y libros sobre alguna materia o profesión, libros de texto o de uso universitario $(35.5 \%)$.

Asimismo, se reporta que el porcentaje de lectores de algún material es mayor conforme se incrementa el nivel educativo, de tal forma que quienes más leen, han cursado al menos un grado de educación superior. En relación con lo anterior, el contexto universitario es terreno fértil para la lectura. Al respecto, la Encuesta Nacional sobre Consumo Digital y Lectura entre Jóvenes Mexicanos (IBBY MÉXICO, 2019), reporta que al $85 \%$ de los universitarios les gusta leer; leen 6.5 libros en promedio al año; leen más por gusto (3.5 libros) que por obligación (3.0), y entre lo que acostumbran leer están las obras literarias: novela, poesía y cuentos.

Como señala Argüelles (2017), si bien es deseable que las personas lean más (e indicadores duros como los anteriores, nos acercan al comportamiento lector de una población), es importante interesarse por otros aspectos relevantes como qué leer y para qué. En última instancia, interesarnos por si la lectura realmente nos hace mejores personas. Esta sugerencia motiva la presente investigación, que se enfoca en el ámbito universitario y cuyo marco de referencia apela al desarrollo integral del hombre y a la lectura de obras literarias como fuente potencial de formación integral, de las que emanan saberes que pueden incidir en el proceso de humanización. En este sentido, es de especial 
relevancia el papel que juegan las instituciones educativas en la promoción de la cultura y la formación de sus estudiantes, para lo cual, el fomento y la experiencia de la lectura por gusto y desde una mirada crítica, es fundamental.

\section{MARCO TEÓRICO}

\section{Humanización y cultura}

Para Sobrevilla (1998), la cultura puede definirse en un sentido figurado -ya sea objetivo-, como toda creación del ser humano, material, y espiritual -o subjetivo-, como el cultivo del hombre y de sus facultades. En el sentido subjetivo, el protagonista es el hombre en sus dimensiones natural y espiritual, siendo esta última, de acuerdo con Scheler (2003), la que lo distingue y encumbra por el resto de las especies. Esta dimensión espiritual -que le permite tener conciencia de sí mismo y del mundo-, lo lleva a su vez a experimentar una serie de contradicciones o dicotomías existenciales que constituyen su condición humana (Fromm, 1980): a) se descubre un ser vivo que morirá; b) su existencia es breve comparada con la historia de la humanidad y esto lo lleva a buscar un sentido de realización o trascendencia, y c) es un individuo independiente y a la vez un ser social.

En última instancia, señala Arendt (2017), todo lo que el hombre produce o con lo que está en contacto, se vuelve condición de su existencia. Así pues, para afrontar su condición humana y dar respuesta a las preguntas que esta le plantea, el hombre ha de valerse de la cultura (Pérez, 1995). En esta misma línea, Scheler (1937) señala que, a fin de que el hombre cumpla con la vocación última de su dimensión espiritual -esto es, llegar a ser hombre-, debe transitar por un proceso de humanización a través de la cultura. De ella debe extraer modelos valiosos de persona que guíen el desarrollo de sus potencialidades en sus diferentes dimensiones (profesional, ética, moral, artística, etcétera), y pueda servirse del saber que, en relación con sus fines, se clasifica en saber pragmático (el saber de la ciencia que nos permite comprender y transformar el mundo); saber culto (saber asimilado, digerido como una segunda naturaleza que guía el pleno desenvolvimiento del hombre: actitudes, acciones, decisiones, etcétera), y saber de salvación (cuyo fin es la Divinidad, participar del ser y fundamento supremo esencial y existencial). Y si bien, todos los saberes son importantes y han de guardar un equilibrio, interesa de manera particular el saber culto, que permea en el desenvolvimiento integral del hombre. Este se manifiesta de forma unitaria o integral, a través de sus actos (Pérez, 2010), de acuerdo con los saberes que posee y permean su cultura, y esos actos lo humanizan o lo deshumanizan.

En este sentido, según Fromm, citado por Rivas (2013), en el hombre existen tendencias de vida (crecimiento, cambio, desarrollo, evolución, progreso, creación, etcétera) y de muerte (estancamiento, retroceso, repetición, destrucción...), como modos de relacionarse con el mundo, con los demás y consigo mismo. Tendencias que se traducen en actos de humanización o deshumanización en la experiencia humana respectivamente. Y si tal es la importancia del saber culto, cabe preguntarse entonces, ¿cómo puede el hombre acceder a este tipo de saber que ha de confrontarlo con su condición humana y guiarlo en su proceso de humanización? Encontramos una respuesta en la obra literaria. 


\section{Importancia de la literatura}

Se alude a la obra literaria en pureza, como la refiere Reyes (1944), cuyos géneros son el poético, el narrativo y el dramático, y que presentan al hombre en su naturaleza esencial, a diferencia de la no literatura, que solo reviste al hombre de conocimientos especializados, tal es el caso de los textos profesionalizantes. En general y de acuerdo con diferentes autores, la importancia de la literatura se puede resumir como sigue:

a) Funge como receptáculo y transmisor de la condición y la experiencia humana. Es decir, expone el común denominador de la cultura de la humanidad, que permite a los seres humanos «coexistir, comunicarse y sentirse de alguna manera solidarios» (Vargas, 2000, párr. 4). En palabras de Steiner (2003), «la literatura se ocupa esencial y continuamente de la imagen del hombre, de la conformación y los motivos de la conducta humana» (pp. 21-22).

b) Es un medio para el crecimiento espiritual del hombre. Al ser una obra de arte, apela a la belleza, a la sensibilidad estética y al ennoblecimiento del espíritu (Álzaga, 2001). Es una fuente potencial para transformar al hombre. De ella emanan saberes que podrían traducirse en actos humanizadores, que calen en la propia experiencia y contribuyan en la formación de mejores personas. Lo anterior, sin caer en la ingenuidad de que la literatura, por sí misma, es suficiente (Argüelles, 2017).

c) Como medio para conocerse a sí mismo y a los otros. Los personajes de una obra literaria, nos permiten ampliar nuestras experiencias, vivir otras vidas, contrastar quiénes somos con lo que ellos son, y brindarnos una experiencia de reconocimiento y crecimiento (Álzaga, 2001). En definitiva, permite descubrir arquetipos (Eco, 2017; García, 1993), modelos y anti-modelos de conducta.

d) Como medio de evasión. El hombre transita de su mundo primario o real, a un mundo secundario o de fantasía sub-creada, para evadirse de aquello que aqueja su dimensión natural y espiritual, o para buscar satisfacción, consuelo o anhelos (Tolkien, 1994).

e) Dado todo lo anterior, la literatura es una fuente potencial para la formación integral, cuando esta, según Larrosa (2003), «nos forma (nos de-forma o nos transforma), como algo que nos constituye o nos pone en cuestión en aquello que somos» (p. 26) y nos afecta en lo propio. Para López (1994), se pueden extraer de la obra literaria los procesos espirituales de los protagonistas para la construcción o destrucción de su personalidad, lo que llama experiencias de éxtasis y de vértigo, que podríamos considerar como experiencias de vida y muerte, de humanización o deshumanización, como ya se ha referido.

Pero el poder transformador de la literatura no opera mágicamente, ni un texto tiene el mismo efecto en todos los lectores. Como señala Larrosa (2003), la experiencia de la lectura no puede ser causada o anticipada, solo pueden cuidarse determinadas condiciones de posibilidad, como el texto, el momento y la sensibilidad adecuados. Se debe tener apertura y la disposición de ánimo para la reflexión que posibilita al lector extraer lo esencial de la experiencia humana de los personajes para que, tomando cierta perspectiva de análisis, el lector logre identificarse con aquello que beneficie su propio desarrollo personal y la configuración de su personalidad. No obstante, para que la lectura de obras literarias no se quede en una exquisita trivialidad (Argüelles, 2017) y cale en el proceso de humanización, es necesario dejar que nos transforme, es decir, hacerla vida. 


\section{Hacer vida la lectura}

Como se ha reseñado, se apela a la obra literaria con el anhelo de que, leerla, nos hará más humanos; mejores personas. Para Manguel (2014), el mundo puede ser visto como un libro que pretendemos leer, un mundo que se encuentra en los libros. En esta metáfora tienen cabida tres tipos de lectores: el viajero, la torre y la larva, los cuales, como se verá, guardan cierta correspondencia con los saberes y el proceso de humanización que propone Scheler (1937).

Para Manguel (2014), el lector viajero es aquel que hace vida la lectura. En esta línea, Zaid (1982) señala que lo importante es que la lectura nos haga más reales, que nuestra forma de ser cambie porque lo leído tuvo algo que decirnos. Esto ocurre cuando el lector extrae de la obra literaria, modelos de conducta y saberes que permearán en su cultura y se traducirán en actos de humanización o deshumanización. En cuanto al segundo tipo de lector, supongamos que ese lector viajero decide retraerse del mundo en una torre y abandonar el viaje con uno de dos fines (Manguel, 2014, pp. 64, 71):

a) Buscar un refugio para comprender el mundo, estudiarlo, alimentar su vida interior, explorar otra visión o perspectiva y, volver entonces, con anhelo renovado y transformador, para seguir viajando (como han hecho sabios, filósofos, científicos, intelectuales, etcétera).

b) Escapar y aislarse, convirtiendo los libros en el bien más preciado en sí mismo, pero sin que le interese el mundo ni la sociedad (p. 13), sino la pedantería, la erudición narcisista e individualista, y el hacer de sí mismo, como apunta Scheler (1937), una obra de arte, lo cual es vano, porque saber por saber no se traduce en el ser y en la experiencia de vida. Pero aún hay un estadio más: la larva, el devoralibros que es, a su vez, devorado por el texto para evadirse completamente de la realidad, sin que encuentre conexión alguna ni beneficio para su vida o su cultura. Este es el lector que no lee para vivir, sino que vive para leer (Manguel, 2014).

¿Qué tipo de lector se es? Quizá frente a un texto se adopta más de una postura. Ante la pasión por la lectura, también es preciso encontrar un equilibrio para extraer los saberes que han de servir al proceso de humanización.

En suma, la literatura se considera una fuente potencial de formación integral, pues evidencia la relación del hombre consigo mismo, con los otros y con el mundo (pensamiento, acciones, anhelos, pasiones, conflictos y contradicciones, etcétera). Por eso es importante fomentar la práctica de la lectura de obras literarias por gusto, con una mirada crítica y apelando a su poder transformador.

Para el contexto universitario de interés, Alexander Astin (1984) señala que las acciones y prácticas de la institución son determinantes en el grado de involucramiento de los estudiantes en su vida universitaria, lo cual repercute en su desarrollo, no solo académico sino también personal (Torres, 2009). Las instituciones están llamadas a diseñar e implementar programas acordes con los intereses y las necesidades del estudiantado, para favorecer su desarrollo y la promoción de la cultura. El reto en el ámbito de la lectura, no es solo lograr que los estudiantes lean más, sino conseguir que vivan una experiencia de lectura significativa. Para ello, es importante conocer el perfil lector de los estudiantes como punto de partida. 


\section{MÉTODO}

En el marco anterior, el objetivo de la investigación es conocer el perfil lector literario del universitario de primer semestre, a fin de brindar información pertinente y oportuna para el diseño de programas o prácticas que fomenten la lectura de obras literarias durante su vida universitaria. Para ello, la investigación se realizó en una universidad privada en México, en cuya misión se plantea la formación integral que se traduce en lo profesional, intelectual, humano, social y espiritual, como consta en su modelo educativo. Por tanto, es una institución propicia para impulsar la lectura de obras literarias como fuente potencial de formación integral.

En este contexto, se plantea la pregunta general de investigación: ¿Cuál es el perfil lector-literario de los estudiantes de primer semestre? Y las preguntas específicas: ¿Qué tanto les gusta leer literatura?, ¿qué tanto leen literatura?, ¿qué importancia conceden a la lectura de obras literarias?, ¿con qué frecuencia hacen vida la literatura?, ¿en qué medida les gustaría participar en actividades promotoras de la lectura de obras literarias, si se ofrecieran en su universidad? Para responder a estas preguntas, el estudio es de corte cuantitativo, de diseño no experimental, transeccional y de alcance descriptivo.

El instrumento de medición consistió en un cuestionario auto aplicado en línea, elaborado a partir de los autores del marco teórico y de las prácticas de fomento a la lectura existentes en la universidad, así como otras opciones complementarias consideradas de interés. La Tabla 1 presenta las ocho variables de la investigación, su descripción y operacionalización, a partir del instrumento de 29 reactivos: tres sobre características del estudiante (sexo, edad y carrera que cursa) y 26 reactivos para medir las variables principales (Gusto por la lectura de obras literarias; Número de obras literarias leídas; Importancia de la literatura; Hacer vida la lectura de obras literarias, y Actividades promotoras de la lectura de obras literarias).

La propuesta inicial del instrumento para este estudio, se conformó por 36 reactivos: tres sobre características del estudiante, 32 para medir las variables principales y una pregunta abierta para solicitar al estudiante sugerencias de prácticas promotoras de la lectura que fueran de su interés a fin de complementar, de ser necesario, la lista que previamente se tenía definida. Esta versión se sometió al juicio de cuatro expertos, que valoraron: a) si los reactivos eran claros en su redacción; b) relevantes para responder a las preguntas de investigación, y c) si las opciones de respuesta eran claras y suficientes. Después de la retroalimentación, se aplicaron pequeños ajustes en la redacción de dos reactivos y en las opciones de respuesta de una escala.

El instrumento validado por expertos se sometió a una prueba piloto con una muestra de 101 estudiantes de los primeros semestres, para asegurar su confiabilidad y validez. Al respecto, para las escalas sobre la Importancia de la literatura, Hacer vida la lectura de obras literarias y Actividades promotoras de la lectura de obras literarias, se obtuvo una muy buena confiabilidad con un Alpha de Cronbach de 0.88, 0.81 y 0.89 respectivamente. De los análisis factoriales realizados para las tres variables, bajo el criterio de extracción de autovalores $>1$, método de extracción por máxima verosimilitud y rotación Promax, se concluyó la conveniencia de excluir seis reactivos debido a su baja saturación, porque saturaban en más de un factor o por no ser suficientemente representativos de la variable en cuestión. Asimismo, se ajustó la redacción de tres reactivos. De esta forma, el instrumento final quedó conformado por los 29 reactivos de la tabla siguiente. 


\section{Tabla 1}

Variables y su operacionalización

\begin{tabular}{|c|c|c|c|c|c|c|}
\hline \multicolumn{4}{|c|}{ VARIABLE } & \multicolumn{3}{|c|}{ OPERACIONALIZACIÓN } \\
\hline No. & Nombre & Descripción & $\begin{array}{l}\text { Nivel de } \\
\text { medición }\end{array}$ & ID & Reactivo & Valores \\
\hline 1 & Sexo. & $\begin{array}{l}\text { Se refiere a la } \\
\text { clasificación en } \\
\text { masculino y } \\
\text { femenino. } \\
\end{array}$ & Nominal. & a & Sexo. & $\begin{array}{l}\text { Masculino. } \\
\text { Femenino. }\end{array}$ \\
\hline 2 & Edad. & $\begin{array}{l}\text { Número de años } \\
\text { cumplidos. }\end{array}$ & Razón. & $\mathrm{b}$ & Edad (años cumplidos). & Número entero. \\
\hline 3 & Carrera. & $\begin{array}{l}\text { Programa } \\
\text { académico que cursa } \\
\text { el estudiante en la } \\
\text { universidad. }\end{array}$ & Nominal. & C & Carrera. & $\begin{array}{l}\text { Oferta académica } \\
\text { de la universidad } \\
\text { al momento de } \\
\text { la aplicación del } \\
\text { instrumento. }\end{array}$ \\
\hline 4 & $\begin{array}{l}\text { Gusto por } \\
\text { la lectura } \\
\text { de obras } \\
\text { literarias. }\end{array}$ & $\begin{array}{l}\text { Medida en que al } \\
\text { estudiante le gusta } \\
\text { la lectura de obras } \\
\text { literarias (novela, } \\
\text { cuento, obra de } \\
\text { teatro, poesía). } \\
\end{array}$ & Ordinal. & R1 & $\begin{array}{l}\text { ¿Qué tanto te gusta } \\
\text { leer obras literarias? } \\
\text { Ejemplos: novela, cuento, } \\
\text { obra de teatro, poesía, } \\
\text { etcétera. }\end{array}$ & $\begin{array}{l}\text { (1) Nada. } \\
\text { (2) Poco. } \\
\text { (3) Regular. } \\
\text { (4) Mucho. }\end{array}$ \\
\hline 5 & $\begin{array}{c}\text { Número de } \\
\text { obras literarias } \\
\text { terminadas. }\end{array}$ & $\begin{array}{l}\text { Número de obras } \\
\text { literarias leídas en } \\
\text { los últimos doce } \\
\text { meses (terminadas). }\end{array}$ & Razón. & $\mathrm{R} 2$ & $\begin{array}{l}\text { Del TOTAL de libros } \\
\text { leídos en los últimos doce } \\
\text { meses, ¿cuántos fueron } \\
\text { OBRAS LITERARIAS } \\
\text { (novelas, libros de } \\
\text { cuentos, obras de } \\
\text { teatro, libros de poesía, } \\
\text { etcétera)? Número de } \\
\text { libros terminados. }\end{array}$ & $\begin{array}{l}\text { Número entero } \\
\text { entre } 0 \text { y } \mathrm{N} \text {. }\end{array}$ \\
\hline
\end{tabular}




\begin{tabular}{|c|c|c|c|c|c|c|}
\hline \multirow{7}{*}{6} & \multirow{7}{*}{$\begin{array}{c}\text { Importancia } \\
\text { de la } \\
\text { literatura. }\end{array}$} & \multirow{7}{*}{$\begin{array}{l}\text { Nivel promedio } \\
\text { de acuerdo o } \\
\text { desacuerdo respecto } \\
\text { a la importancia } \\
\text { de la literatura, } \\
\text { como una forma } \\
\text { de favorecer el } \\
\text { conocimiento de } \\
\text { uno mismo, de los } \\
\text { otros y del mundo; } \\
\text { como un medio } \\
\text { de formación en } \\
\text { valores; como } \\
\text { contribución } \\
\text { para ser mejores } \\
\text { personas; identificar } \\
\text { la experiencia y la } \\
\text { condición humana } \\
\text { reflejada en los } \\
\text { personajes de los } \\
\text { libros; conocer y } \\
\text { entender nuestra } \\
\text { cultura y la de otros } \\
\text { pueblos; identificar } \\
\text { modelos y anti } \\
\text { modelos; y acceder } \\
\text { a saberes, historias } \\
\text { y experiencias de la } \\
\text { humanidad para dar } \\
\text { sentido a la propia } \\
\text { existencia. }\end{array}$} & \multirow{7}{*}{ Intervalar. } & R3 & $\begin{array}{l}\text { Favorece el conocimiento } \\
\text { de uno mismo, de los } \\
\text { otros y del mundo, al } \\
\text { contrastar la realidad con } \\
\text { el contexto de la obra y } \\
\text { los personajes literarios. }\end{array}$ & \multirow{7}{*}{$\begin{array}{l}\text { (1) Totalmente en } \\
\text { desacuerdo. } \\
\text { (2) En desacuerdo. } \\
\text { (3) Ni de acuerdo } \\
\text { ni en desacuerdo. } \\
\text { (4) De acuerdo. } \\
\text { (5) Totalmente de } \\
\text { acuerdo. }\end{array}$} \\
\hline & & & & $\mathrm{R} 4$ & $\begin{array}{l}\text { Es un medio de } \\
\text { formación en valores. }\end{array}$ & \\
\hline & & & & R5 & $\begin{array}{l}\text { Leer obras literarias } \\
\text { puede contribuir (entre } \\
\text { otros aspectos) a que } \\
\text { seamos mejores personas. }\end{array}$ & \\
\hline & & & & R6 & $\begin{array}{l}\text { En los personajes de } \\
\text { los libros, se refleja la } \\
\text { experiencia o la condición } \\
\text { humana (cualidades, } \\
\text { defectos, pensamiento, } \\
\text { sentimientos y } \\
\text { acciones; anhelos, } \\
\text { pasiones, conflictos y } \\
\text { contradicciones, etcétera). }\end{array}$ & \\
\hline & & & & R7 & $\begin{array}{l}\text { La literatura nos permite } \\
\text { conocer y entender } \\
\text { nuestra cultura y la } \\
\text { cultura de otros pueblos } \\
\text { (creencias, costumbres, } \\
\text { contextos, expresiones } \\
\text { artísticas, etcétera). }\end{array}$ & \\
\hline & & & & R8 & $\begin{array}{l}\text { Permite identificar en los } \\
\text { personajes, modelos a } \\
\text { seguir y anti modelos a } \\
\text { evitar. }\end{array}$ & \\
\hline & & & & R9 & $\begin{array}{l}\text { La literatura me } \\
\text { permite acceder a } \\
\text { saberes, historias y } \\
\text { experiencias de la } \\
\text { humanidad (favorables } \\
\text { y desfavorables) que, al } \\
\text { interpretarlas, cobran } \\
\text { sentido para mi propia } \\
\text { existencia. }\end{array}$ & \\
\hline
\end{tabular}




\begin{tabular}{|c|c|c|c|c|c|c|}
\hline \multirow{7}{*}{7} & \multirow{7}{*}{$\begin{array}{l}\text { Hacer vida } \\
\text { la lectura } \\
\text { de obras } \\
\text { literarias. }\end{array}$} & \multirow{7}{*}{$\begin{array}{l}\text { Frecuencia } \\
\text { promedio con la que } \\
\text { el estudiante hace } \\
\text { vida la literatura, lo } \\
\text { cual se traduce en: } \\
\text { reflexionar sobre } \\
\text { el mensaje de la } \\
\text { obra; identificar } \\
\text { qué aspectos, } \\
\text { actitudes y acciones } \\
\text { de los personajes } \\
\text { se asemejan a la } \\
\text { vida real; sentir } \\
\text { empatía por las } \\
\text { circunstancias de } \\
\text { los personajes; } \\
\text { identificar } \\
\text { enseñanzas y } \\
\text { valores aplicables } \\
\text { a la propia vida; } \\
\text { poner en práctica } \\
\text { las enseñanzas de la } \\
\text { obra literaria para } \\
\text { la mejora; compartir } \\
\text { reflexiones con } \\
\text { otras personas, y la } \\
\text { frecuencia con que } \\
\text { la lectura cambia la } \\
\text { perspectiva sobre } \\
\text { algún aspecto. }\end{array}$} & \multirow{7}{*}{ Intervalar. } & R10 & $\begin{array}{l}\text { Reflexionas sobre el } \\
\text { mensaje de la obra. }\end{array}$ & \multirow{7}{*}{$\begin{array}{l}\text { (1) Nunca. } \\
\text { (2) Algunas veces. } \\
\text { (3) } \\
\text { Frecuentemente. } \\
\text { (4) Muy } \\
\text { frecuentemente. } \\
\text { (5) Siempre. }\end{array}$} \\
\hline & & & & R11 & $\begin{array}{l}\text { Identificas qué aspectos } \\
\text { de la historia o de las } \\
\text { actitudes y acciones } \\
\text { de los personajes se } \\
\text { asemejan a la vida real. }\end{array}$ & \\
\hline & & & & R12 & $\begin{array}{l}\text { Sientes empatía por } \\
\text { las circunstancias } \\
\text { de los personajes, } \\
\text { ya sean favorables o } \\
\text { desfavorables (penas, } \\
\text { alegrías, problemas, } \\
\text { aciertos, desaciertos, } \\
\text { etcétera). }\end{array}$ & \\
\hline & & & & R13 & $\begin{array}{l}\text { Identificas qué } \\
\text { enseñanzas y valores son } \\
\text { aplicables a tu propia } \\
\text { vida. }\end{array}$ & \\
\hline & & & & R14 & $\begin{array}{l}\text { Pones en práctica las } \\
\text { enseñanzas de la obra } \\
\text { literaria para mejorar } \\
\text { algún aspecto de tu vida. }\end{array}$ & \\
\hline & & & & R15 & $\begin{array}{l}\text { Compartes con otras } \\
\text { personas las reflexiones o } \\
\text { enseñanzas que te dejó la } \\
\text { obra literaria. } \\
\end{array}$ & \\
\hline & & & & R16 & $\begin{array}{l}\text { Después de leer, ciertos } \\
\text { aspectos de la vida } \\
\text { relacionados con el } \\
\text { texto, los ves desde otra } \\
\text { perspectiva. }\end{array}$ & \\
\hline
\end{tabular}




\begin{tabular}{|c|c|c|c|c|c|c|}
\hline \multirow{10}{*}{8} & \multirow{10}{*}{$\begin{array}{c}\text { Actividades } \\
\text { promotoras } \\
\text { de la lectura } \\
\text { de obras } \\
\text { literarias. }\end{array}$} & \multirow{10}{*}{$\begin{array}{l}\text { Nivel promedio en } \\
\text { el que le gustaría } \\
\text { participar al } \\
\text { estudiante, en } \\
\text { diversas actividades } \\
\text { promotoras de } \\
\text { la lectura si se } \\
\text { ofrecieran en } \\
\text { su universidad, } \\
\text { tal es el caso de: } \\
\text { pertenecer a un club } \\
\text { de lectura; asistir } \\
\text { a presentaciones } \\
\text { de obras literarias } \\
\text { por parte de } \\
\text { los escritores, a } \\
\text { conferencias, foros o } \\
\text { paneles de expertos } \\
\text { sobre literatura; } \\
\text { en un maratón o } \\
\text { concurso de lectura } \\
\text { en voz alta; cursos o } \\
\text { talleres relacionados } \\
\text { con la lectura o } \\
\text { literatura; participar } \\
\text { en foros donde } \\
\text { se hable de obras } \\
\text { literarias; escuchar } \\
\text { o participar en } \\
\text { programas de Radio } \\
\text { Anáhuac en los que } \\
\text { se comenten obras } \\
\text { literarias; recibir } \\
\text { material impreso } \\
\text { o digital con } \\
\text { recomendaciones; } \\
\text { recibir notificaciones } \\
\text { de las últimas } \\
\text { adquisiciones } \\
\text { literarias en } \\
\text { biblioteca; asistir a } \\
\text { ferias de libro, y que } \\
\text { la lectura de obras } \\
\text { literarias sea parte } \\
\text { de algunas materias } \\
\text { de su carrera. }\end{array}$} & \multirow{10}{*}{ Intervalar. } & R17 & $\begin{array}{l}\text { Formar parte de un club } \\
\text { de lectura en el que, } \\
\text { periódicamente, se leen y } \\
\text { comentan obras literarias } \\
\text { (grupo coordinado por } \\
\text { un moderador). }\end{array}$ & \multirow{10}{*}{$\begin{array}{l}\text { (1) Nada. } \\
\text { (2) Poco. } \\
\text { (3) Regular. } \\
\text { (4) Mucho. }\end{array}$} \\
\hline & & & & R18 & $\begin{array}{l}\text { Asistir a presentaciones } \\
\text { de obras literarias, por } \\
\text { parte de los escritores, en } \\
\text { la universidad. }\end{array}$ & \\
\hline & & & & R19 & $\begin{array}{l}\text { Asistir a conferencias, } \\
\text { foros o paneles de } \\
\text { expertos donde se } \\
\text { hable de obras literarias } \\
\text { (importancia literaria y } \\
\text { formativa, descripción de } \\
\text { los personajes, mensaje } \\
\text { de la obra, contexto } \\
\text { histórico, adaptación al } \\
\text { cine, en su caso, etcétera). }\end{array}$ & \\
\hline & & & & R20 & $\begin{array}{l}\text { Participar en un maratón } \\
\text { o concurso de lectura en } \\
\text { voz alta. }\end{array}$ & \\
\hline & & & & R21 & $\begin{array}{l}\text { Asistir a cursos o } \\
\text { talleres relacionados } \\
\text { con la lectura o la } \\
\text { literatura (ejemplos: } \\
\text { lectura rápida, géneros } \\
\text { literarios, formación } \\
\text { como cuentacuentos o } \\
\text { booktuber, etcétera). }\end{array}$ & \\
\hline & & & & R22 & $\begin{array}{l}\text { Escuchar o participar en } \\
\text { un programa de Radio } \\
\text { Anáhuac, en el que se } \\
\text { comenten obras literarias. }\end{array}$ & \\
\hline & & & & R23 & $\begin{array}{l}\text { Recibir material impreso } \\
\text { o digital (boletines, } \\
\text { revistas, videos, } \\
\text { imágenes, etcétera), con } \\
\text { recomendaciones de } \\
\text { obras literarias. }\end{array}$ & \\
\hline & & & & R24 & $\begin{array}{l}\text { Recibir notificaciones de } \\
\text { las últimas adquisiciones } \\
\text { literarias de la biblioteca. }\end{array}$ & \\
\hline & & & & R25 & $\begin{array}{l}\text { Asistir a ferias de } \\
\text { libro para enterarte de } \\
\text { novedades literarias. } \\
\text { Acudir a la presentación } \\
\text { de un libro o adquirir } \\
\text { libros. }\end{array}$ & \\
\hline & & & & R26 & $\begin{array}{l}\text { ¿Qué tanto te gustaría } \\
\text { que la lectura de obras } \\
\text { literarias fuera parte } \\
\text { de algunas materias } \\
\text { formativas de tu carrera? } \\
\text { Por ejemplo, materias de } \\
\text { corte humanístico. }\end{array}$ & \\
\hline
\end{tabular}


El instrumento final se aplicó a una muestra por conveniencia de 1,111 estudiantes de primer semestre, inscritos en 43 programas académicos de nivel licenciatura. Del total de la muestra, el 59\% son mujeres (656) y el $41 \%$ hombres (455). La mayoría (80\%) de 18 o 19 años de edad.

El procesamiento de resultados considera, como base, el análisis de conglomerados para la identificación de los perfiles, y estadística descriptiva para su caracterización: distribución de frecuencias, medias y porcentajes Top Two Boxes (TTB), que considera las dos opciones de respuesta más favorables en la escala de medición.

\section{ESTUDIO DEL INSTRUMENTO}

En cuanto al estudio del instrumento (reactivos R3 a R26), considerando los 1,111 casos, la validez de constructo de acuerdo con el análisis factorial por Componentes Principales y rotación Promax con Autovalores > 1, explica el 59\% de la varianza y respalda la estructura teórica arrojando tres factores. La confiabilidad (Alpha de Cronbach) de cada factor está en torno 0.9 , lo cual se considera muy favorable:

\section{Tabla 2}

Estudio del instrumento (confiabilidad y validez de constructo)

\begin{tabular}{|c|c|c|c|c|c|}
\hline \multirow[b]{2}{*}{ Variable } & \multirow[b]{2}{*}{ Reactivo } & \multicolumn{3}{|c|}{ COMPONENTES } & \multirow{2}{*}{$\begin{array}{l}\text { CONFIABILIDAD } \\
\text { Alpha de Cronbach }\end{array}$} \\
\hline & & 1 & 2 & 3 & \\
\hline \multirow{10}{*}{$\begin{array}{l}\text { Actividades } \\
\text { promotoras } \\
\text { de la lectura } \\
\text { de obras } \\
\text { literarias. }\end{array}$} & R21 & 0.818 & & & \multirow{10}{*}{0.91} \\
\hline & $\mathrm{R} 24$ & 0.794 & & & \\
\hline & R18 & 0.782 & & & \\
\hline & $\mathrm{R} 22$ & 0.781 & & & \\
\hline & R17 & 0.779 & & & \\
\hline & R19 & 0.747 & & & \\
\hline & $\mathrm{R} 25$ & 0.732 & & & \\
\hline & $\mathrm{R} 23$ & 0.73 & & & \\
\hline & $\mathrm{R} 20$ & 0.691 & & & \\
\hline & $\mathrm{R} 26$ & 0.589 & & & \\
\hline \multirow{7}{*}{$\begin{array}{l}\text { Importancia } \\
\text { de la } \\
\text { literatura. }\end{array}$} & R7 & & 0.849 & & \multirow{7}{*}{0.89} \\
\hline & R9 & & 0.821 & & \\
\hline & R8 & & 0.782 & & \\
\hline & R5 & & 0.755 & & \\
\hline & R4 & & 0.749 & & \\
\hline & R6 & & 0.736 & & \\
\hline & R3 & & 0.687 & & \\
\hline
\end{tabular}




\begin{tabular}{|c|c|c|c|}
\hline \multirow{7}{*}{$\begin{array}{l}\text { Hacer vida } \\
\text { la lectura } \\
\text { de obras } \\
\text { literarias. }\end{array}$} & R14 & 0.834 & \multirow{7}{*}{0.89} \\
\hline & R13 & 0.807 & \\
\hline & R15 & 0.792 & \\
\hline & R16 & 0.787 & \\
\hline & R11 & 0.785 & \\
\hline & R10 & 0.726 & \\
\hline & R12 & 0.59 & \\
\hline
\end{tabular}

\section{RESULTADOS}

Se presentan en esta sección las preguntas de investigación y los hallazgos correspondientes.

¿Cuál es el perfil lector-literario de los estudiantes de primer semestre?

Para responder a la pregunta general de investigación, se realizó un análisis de conglomerados jerárquicos por el método de Ward, distancia euclídea al cuadrado y selección de tres clusters, utilizando las variables: Gusto por la lectura de obras literarias; Importancia de la literatura; Hacer vida la lectura de obras literarias, y Actividades promotoras de la lectura de obras literarias.

De acuerdo con los resultados, se obtienen tres perfiles o niveles de disposición ante la lectura de obras literarias: bajo, medio y alto. El mayor porcentaje de estudiantes de primer semestre se ubica en el perfil de nivel medio (532 estudiantes - 47.1\%), seguido por el nivel alto (349 estudiantes - 31.4\%), y el menor porcentaje en nivel bajo (239 estudiantes - 21.5\%).

La caracterización de los perfiles responde a las preguntas específicas: ¿Qué tanto les gusta leer literatura?, ¿qué tanto leen literatura?, ¿qué importancia conceden a la lectura de obras literarias?, ¿con qué frecuencia hacen vida la literatura?, ¿en qué medida les gustaría participar en actividades promotoras de la lectura de obras literarias, si se ofrecieran en su universidad? En la descripción del primer perfil se anota la referencia a las tablas de resultados correspondientes:

El perfil lector literario de nivel bajo, lo conforman en su mayoría hombres (59.4\%) (Tabla 3), y la literatura les gusta poco $(51.9 \%)$ o nada (40.2\%) (Tabla 4). De hecho, la gran mayoría solo leyó entre una y tres obras literarias en el último año (76.4\%) (Tabla 5).

En cuanto a la importancia que conceden a la lectura de obras literarias, en la escala del 1 al 5, el puntaje promedio de los reactivos que conforman la variable, es de 3.2 (Tabla 6). Considerando el porcentaje de estudiantes que reportaron estar de acuerdo o totalmente de acuerdo (TTB) con los diferentes aspectos (Tabla 7) que conforman la variable, este oscila entre $35.1 \%$ y $53.6 \%$. En general, menos de la mitad está de acuerdo o totalmente de acuerdo, con que la literatura «Permite identificar en los personajes, modelos a seguir y anti modelos a evitar» $(40.6 \%)$ y que «Leer obras literarias puede contribuir (entre otros aspectos) a que seamos mejores personas» $(35.1 \%)$.

Respecto a hacer vida la lectura de obras literarias, en la escala del 1 al 5 alcanzó un promedio de 2.3 (Tabla 6). El \% TTB de los reactivos que conforman esta variable (Tabla 8) oscila entre el $4.6 \%$ y el $15.5 \%$ de estudiantes que señalaron experimentar muy frecuentemente o 
siempre, los diferentes aspectos considerados. Solo el $8.4 \%$ reportó que muy frecuentemente o siempre «Pone en práctica las enseñanzas de la obra literaria para mejorar algún aspecto de su vida».

En lo correspondiente a las actividades promotoras de la lectura de obras literarias, en la escala de 1 a 4, a los estudiantes del perfil bajo les gustaría participar en promedio 1.7 (Tabla 6). El porcentaje de estudiantes a los que les gustaría participar de manera regular o mucho (TTB), solo va del 7.9\% al 19.7\%, en las diferentes actividades (Tabla 9).

En el perfil lector literario de nivel medio, más de la mitad son mujeres (59.7\%), y a la mayoría le gusta de manera regular la literatura (57.9\%). Si bien la gran mayoría leyó entre una y tres obras literarias el último año $(61.9 \%)$, el segundo mayor porcentaje leyó entre 4 y 6 obras $(21.8 \%)$.

En cuanto a la importancia que conceden a la lectura de obras literarias (escala del 1 al 5), el puntaje promedio de los reactivos que conforman la variable, es de 4.1. El porcentaje de estudiantes que reportaron estar de acuerdo o totalmente de acuerdo en los diferentes aspectos, va del $63.3 \%$ al $82.6 \%$. En este grupo, más de la mitad considera que la literatura «Permite identificar en los personajes, modelos a seguir y anti modelos a evitar» $(69.6 \%)$ y que «Leer obras literarias puede contribuir (entre otros aspectos) a que seamos mejores personas» $(63.3 \%)$.

Respecto a hacer vida la lectura de obras literarias, en la escala del 1 al 5 alcanzó un promedio de 3.1. El porcentaje de estudiantes que señalaron experimentar muy frecuentemente o siempre (TTB), los diferentes aspectos considerados, va del $24.3 \%$ al $50.3 \%$. En este perfil, el $24.3 \%$ de los estudiantes frecuentemente o siempre «Pone en práctica las enseñanzas de la obra literaria para mejorar algún aspecto de su vida».

En lo referente a las actividades promotoras de la lectura de obras literarias, en la escala de 1 a 4 , les gustaría participar, en promedio, 1.8. El porcentaje de estudiantes a quienes les gustaría participar de manera regular o mucho (TTB) va del $15.3 \%$ al $43.6 \%$, en los diferentes reactivos que conforman la variable.

El perfil lector literario de nivel alto, lo conforman mujeres principalmente (70.8\%). A la mayoría le encanta la literatura $(79.4 \%$ ) y a un menor porcentaje le gusta de manera regular $(20.6 \%)$. Menos de la mitad leyeron entre una y tres obras literarias el último año y, el resto, se distribuye en los rangos superiores de cuatro a nueve libros $(28.9 \%)$, de siete a nueve libros $(9.8 \%)$ y de diez o más libros $(18.2 \%)$. En este perfil se identifica el mayor porcentaje de estudiantes que leyó diez libros o más.

Sobre la importancia que conceden a la lectura de obras literarias, en la escala del 1 al 5, el puntaje promedio de los reactivos que conforman la variable, es de 4.4. Son altos los porcentajes de estudiantes que reportaron estar de acuerdo o totalmente de acuerdo (TTB) en los diferentes aspectos, y van del $82.2 \%$ al $96.3 \%$. El $82.2 \%$ considera que la literatura «Permite identificar en los personajes, modelos a seguir y anti modelos a evitar» y el $83.4 \%$ que «Leer obras literarias puede contribuir (entre otros aspectos) a que seamos mejores personas».

Respecto a hacer vida la lectura de obras literarias, en la escala del 1 al 5 alcanzó un promedio de 3.9. Los estudiantes que señalaron experimentar muy frecuentemente o siempre (TTB), los diferentes aspectos considerados, va de $51.6 \%$ a $81.9 \%$. En este grupo, poco más de la mitad de los estudiantes (51.6\%), frecuentemente o siempre «Pone en práctica las enseñanzas de la obra literaria para mejorar algún aspecto de su vida». 
En cuanto a las actividades promotoras de la lectura de obras literarias, el promedio de la intención de participación es de 2.9 en la escala de 1 a 4 . El porcentaje de estudiantes a los que les gustaría participar de manera regular o mucho (TTB), va de $34.1 \%$ al $86 \%$, en las diferentes opciones de promoción consideradas.

\section{Tabla 3}

Distribución de estudiantes por perfil, por sexo

\begin{tabular}{|l|l|l|l|}
\multicolumn{1}{c}{} & \multicolumn{1}{c}{ FEMENINO } & \multicolumn{1}{c}{ MASCULINO } & \multicolumn{1}{c|}{ TOTAL } \\
\hline \multirow{3}{*}{ Perfil bajo. } & 97 & 142 & 239 \\
\cline { 2 - 4 } & $40.6 \%$ & $59.4 \%$ & $100.0 \%$ \\
\hline \multirow{3}{*}{ Perfil medio. } & 312 & 211 & 523 \\
\cline { 2 - 4 } & $59.7 \%$ & $40.3 \%$ & $100.0 \%$ \\
\hline \multirow{3}{*}{ Perfil alto. } & 247 & 102 & 349 \\
\cline { 2 - 4 } & $70.8 \%$ & $29.2 \%$ & $100.0 \%$ \\
\hline \multirow{3}{*}{ Total: } & 656 & 455 & 1111 \\
\cline { 2 - 4 } & $59.0 \%$ & $41.0 \%$ & $100.0 \%$ \\
\hline
\end{tabular}

Tabla 4

Gusto por la lectura de obras literarias

\begin{tabular}{|c|c|c|c|c|c|}
\hline & NADA & POCO & REGULAR & MUCHO & TOTAL \\
\hline \multirow{2}{*}{ Perfil bajo. } & 96 & 124 & 17 & 2 & 239 \\
\hline & $40.2 \%$ & $51.9 \%$ & $7.1 \%$ & $0.8 \%$ & $100.0 \%$ \\
\hline \multirow{2}{*}{ Perfil medio. } & 23 & 80 & 303 & 117 & 523 \\
\hline & $4.4 \%$ & $15.3 \%$ & $57.9 \%$ & $22.4 \%$ & $100.0 \%$ \\
\hline \multirow{2}{*}{ Perfil alto. } & 0 & 0 & 72 & 277 & 349 \\
\hline & $0.0 \%$ & $0.0 \%$ & $20.6 \%$ & $79.4 \%$ & $100.0 \%$ \\
\hline \multirow{2}{*}{ Total: } & 119 & 204 & 392 & 396 & 1111 \\
\hline & $10.7 \%$ & $18.4 \%$ & $35.3 \%$ & $35.6 \%$ & $100.0 \%$ \\
\hline
\end{tabular}




\section{Tabla 5}

Porcentaje de estudiantes de obras literarias leídas en el último año, por rango de número

\begin{tabular}{|c|c|c|c|c|c|}
\hline & \multicolumn{4}{|c|}{ RANGOS } & \multirow{2}{*}{ TOTAL } \\
\hline & 1 a 3 & 4 a 6 & 7 a 9 & $>=10$ & \\
\hline \multirow{2}{*}{ Perfil bajo. } & 107 & 12 & 7 & 14 & 140 \\
\hline & $76.4 \%$ & $8.6 \%$ & $5.0 \%$ & $10.0 \%$ & $100.0 \%$ \\
\hline \multirow{2}{*}{ Perfil medio. } & 270 & 95 & 34 & 37 & 436 \\
\hline & $61.9 \%$ & $21.8 \%$ & $7.8 \%$ & $8.5 \%$ & $100.0 \%$ \\
\hline \multirow{2}{*}{ Perfil alto. } & 140 & 94 & 32 & 59 & 325 \\
\hline & $43.1 \%$ & $28.9 \%$ & $9.8 \%$ & $18.2 \%$ & $100.0 \%$ \\
\hline \multirow{2}{*}{ Total: } & 517 & 201 & 73 & 110 & 901 \\
\hline & $57.4 \%$ & $22.3 \%$ & $8.1 \%$ & $12.2 \%$ & $100.0 \%$ \\
\hline
\end{tabular}

\section{Tabla 6}

Promedios por perfil

\begin{tabular}{|l|l|l|l|}
\hline \multicolumn{1}{|c|}{ PERFILES } & $\begin{array}{c}\text { IMPORTANCIA } \\
\text { DE LA } \\
\text { LITERATURA }\end{array}$ & $\begin{array}{c}\text { HACER VIDA } \\
\text { LA LECTURA } \\
\text { DE OBRAS } \\
\text { LITERARIAS }\end{array}$ & $\begin{array}{c}\text { ACTIVIDADES } \\
\text { PROMOTORAS DE LA } \\
\text { LECTURA DE OBRAS } \\
\text { LITERARIAS }\end{array}$ \\
\hline Nivel bajo. & 3.2 & 2.3 & 1.7 \\
\hline Nivel medio. & 4.1 & 3.1 & 1.8 \\
\hline Nivel alto. & 4.4 & 3.9 & 2.9 \\
\hline Total: & 4.0 & 3.2 & 2.2 \\
\hline
\end{tabular}


Tabla 7

Porcentaje TTB - Importancia de la literatura por perfil

\begin{tabular}{|l|l|l|l|l|}
\hline TOTAL-ESTUDIANTES: & 239 & 523 & 349 & 1,111 \\
\hline
\end{tabular}

\begin{tabular}{|c|c|c|c|c|c|c|c|c|}
\hline \multirow[b]{2}{*}{ Reactivos } & \multicolumn{4}{|c|}{ ТTВ } & \multicolumn{4}{|c|}{$\%$ ТTВ } \\
\hline & Bajo & Medio & Alto & Total & Bajo & Medio & Alto & Total \\
\hline $\begin{array}{l}\text { R7-La literatura nos permite } \\
\text { conocer y entender nuestra } \\
\text { cultura y la cultura de otros } \\
\text { pueblos (creencias, costumbres, } \\
\text { contextos, expresiones artísticas, } \\
\text { etcétera). }\end{array}$ & 128 & 432 & 336 & 896 & $53.6 \%$ & $82.6 \%$ & $96.3 \%$ & $80.6 \%$ \\
\hline $\begin{array}{l}\text { R6-En los personajes de los libros, } \\
\text { se ve reflejada la experiencia o la } \\
\text { condición humana (cualidades, } \\
\text { defectos, pensamiento, } \\
\text { sentimientos y acciones; } \\
\text { anhelos, pasiones, conflictos y } \\
\text { contradicciones, etcétera). }\end{array}$ & 123 & 387 & 325 & 835 & $51.5 \%$ & $74.0 \%$ & $93.1 \%$ & $75.2 \%$ \\
\hline $\begin{array}{l}\text { R9-La literatura me permite } \\
\text { acceder a saberes, historias y } \\
\text { experiencias de la humanidad } \\
\text { (favorables y desfavorables) que, } \\
\text { al interpretarlas, cobran sentido } \\
\text { para mi propia existencia. }\end{array}$ & 103 & 392 & 328 & 823 & $43.1 \%$ & $75.0 \%$ & $94.0 \%$ & $74.1 \%$ \\
\hline $\begin{array}{l}\text { R3-Favorece el conocimiento de } \\
\text { uno mismo, de los otros y del } \\
\text { mundo, al contrastar la realidad } \\
\text { con el contexto de la obra y los } \\
\text { personajes literarios. }\end{array}$ & 85 & 373 & 326 & 784 & $35.6 \%$ & $71.3 \%$ & $93.4 \%$ & $70.6 \%$ \\
\hline $\begin{array}{l}\text { R4-Es un medio de formación en } \\
\text { valores. }\end{array}$ & 92 & 357 & 300 & 749 & $38.5 \%$ & $68.3 \%$ & $86.0 \%$ & $67.4 \%$ \\
\hline $\begin{array}{l}\text { R8-Permite identificar en los } \\
\text { personajes, modelos a seguir y } \\
\text { anti modelos a evitar. }\end{array}$ & 97 & 364 & 287 & 748 & $40.6 \%$ & $69.6 \%$ & $82.2 \%$ & $67.3 \%$ \\
\hline $\begin{array}{l}\text { R5-Leer obras literarias puede } \\
\text { contribuir (entre otros aspectos) a } \\
\text { que seamos mejores personas. }\end{array}$ & 84 & 331 & 291 & 706 & $35.1 \%$ & $63.3 \%$ & $83.4 \%$ & $63.5 \%$ \\
\hline
\end{tabular}


Tabla 8

Porcentaje TTB - Hacer vida la lectura de obras literarias, por perfil

\section{\begin{tabular}{l|l|l|l|l|} 
TOTAL-ESTUDIANTES: & 239 & 523 & 349 & 1,111
\end{tabular}}

\begin{tabular}{|c|c|c|c|c|c|c|c|c|}
\hline \multirow[b]{2}{*}{ Reactivos } & \multicolumn{4}{|c|}{ ТТВ } & \multicolumn{4}{|c|}{$\%$ ТTВ } \\
\hline & Bajo & Medio & Alto & Total & Bajo & Medio & Alto & Total \\
\hline $\begin{array}{l}\text { R12-Sientes empatía por } \\
\text { las circunstancias de } \\
\text { los personajes, ya sean } \\
\text { favorables o desfavorables } \\
\text { (penas, alegrías, problemas, } \\
\text { aciertos, desaciertos, } \\
\text { etcétera). }\end{array}$ & 37 & 263 & 286 & 586 & $15.5 \%$ & $50.3 \%$ & $81.9 \%$ & $52.7 \%$ \\
\hline $\begin{array}{l}\text { R13-Identificas qué } \\
\text { enseñanzas y valores son } \\
\text { aplicables a tu propia vida. }\end{array}$ & 36 & 239 & 251 & 526 & $15.1 \%$ & $45.7 \%$ & $71.9 \%$ & $47.3 \%$ \\
\hline $\begin{array}{l}\text { R11-Identificas qué aspectos } \\
\text { de la historia o de las } \\
\text { actitudes y acciones de los } \\
\text { personajes se asemejan a la } \\
\text { vida real. }\end{array}$ & 21 & 211 & 253 & 485 & $8.8 \%$ & $40.3 \%$ & $72.5 \%$ & $43.7 \%$ \\
\hline $\begin{array}{l}\text { R10-Reflexionas sobre el } \\
\text { mensaje de la obra. }\end{array}$ & 11 & 196 & 245 & 452 & $4.6 \%$ & $37.5 \%$ & $70.2 \%$ & $40.7 \%$ \\
\hline $\begin{array}{l}\text { R16-Después de leer } \\
\text { ciertos aspectos de la vida } \\
\text { relacionados con el texto, los } \\
\text { ves desde otra perspectiva. }\end{array}$ & 19 & 161 & 216 & 396 & $7.9 \%$ & $30.8 \%$ & $61.9 \%$ & $35.6 \%$ \\
\hline $\begin{array}{l}\text { R15-Compartes con otras } \\
\text { personas, las reflexiones o } \\
\text { enseñanzas que te dejó la } \\
\text { obra literaria. }\end{array}$ & 16 & 133 & 193 & 342 & $6.7 \%$ & $25.4 \%$ & $55.3 \%$ & $30.8 \%$ \\
\hline $\begin{array}{l}\text { R14-Pones en práctica } \\
\text { las enseñanzas de la obra } \\
\text { literaria para mejorar algún } \\
\text { aspecto de tu vida. }\end{array}$ & 20 & 127 & 180 & 327 & $8.4 \%$ & $24.3 \%$ & $51.6 \%$ & $29.4 \%$ \\
\hline
\end{tabular}


Tabla 9

Porcentaje TTB - Participación en actividades promotoras de la lectura, por perfil

\begin{tabular}{|l|l|l|l|l|} 
TOTAL-ESTUDIANTES: & 239 & 523 & 349 & 1,111 \\
\hline
\end{tabular}

\begin{tabular}{|c|c|c|c|c|c|c|c|c|}
\hline \multirow[b]{2}{*}{ Reactivos } & \multicolumn{4}{|c|}{ ТTВ } & \multicolumn{4}{|c|}{$\%$ TTB } \\
\hline & Bajo & Medio & Alto & Total & Bajo & Medio & Alto & Total \\
\hline $\begin{array}{l}\text { R25-Asistir a ferias de libro para enterarte de } \\
\text { novedades literarias. Acudir a la presentación } \\
\text { de un libro o adquirir libros. }\end{array}$ & 47 & 228 & 300 & 575 & $19.7 \%$ & $43.6 \%$ & $86.0 \%$ & $51.8 \%$ \\
\hline $\begin{array}{l}\text { R23-Recibir material impreso o digital } \\
\text { (boletines, revistas, videos, imágenes, los ves } \\
\text { desde otra perspectiva), con recomendaciones } \\
\text { de obras literarias. }\end{array}$ & 40 & 209 & 274 & 523 & $16.7 \%$ & $40.0 \%$ & $78.5 \%$ & $47.1 \%$ \\
\hline $\begin{array}{l}\text { R26-¿Qué tanto te gustaría que la lectura de } \\
\text { obras literarias fuera parte de algunas materias } \\
\text { formativas de tu carrera? Por ejemplo, } \\
\text { materias de corte humanístico. }\end{array}$ & 47 & 204 & 260 & 511 & $19.7 \%$ & $39.0 \%$ & $74.5 \%$ & $46.0 \%$ \\
\hline $\begin{array}{l}\text { R19-Asistir a conferencias, foros o paneles de } \\
\text { expertos donde se hable de obras literarias } \\
\text { (importancia literaria y formativa, descripción } \\
\text { de los personajes, mensaje de la obra, contexto } \\
\text { histórico, adaptación al cine, en su caso, los ves } \\
\text { desde otra perspectiva). }\end{array}$ & 39 & 186 & 261 & 486 & $16.3 \%$ & $35.6 \%$ & $74.8 \%$ & $43.7 \%$ \\
\hline $\begin{array}{l}\text { R18-Asitir a presentaciones de obras literarias } \\
\text { en la universidad, por parte de los escritores. }\end{array}$ & 24 & 172 & 280 & 476 & $10.0 \%$ & $32.9 \%$ & $80.2 \%$ & $42.8 \%$ \\
\hline $\begin{array}{l}\text { R24-Recibir notificaciones de las últimas } \\
\text { adquisiciones literarias de la biblioteca. }\end{array}$ & 34 & 175 & 259 & 468 & $14.2 \%$ & $33.5 \%$ & $74.2 \%$ & $42.1 \%$ \\
\hline $\begin{array}{l}\text { R21-Asistir a cursos o talleres relacionados } \\
\text { con la lectura o la literatura (ejemplos: lectura } \\
\text { rápida, géneros literarios, formación como } \\
\text { cuentacuentos o booktuber, etcétera). }\end{array}$ & 27 & 109 & 204 & 340 & $11.3 \%$ & $20.8 \%$ & $58.5 \%$ & $30.6 \%$ \\
\hline $\begin{array}{l}\text { R17-Formar parte de un club de lectura en } \\
\text { el que se leen y comentan obras literarias } \\
\text { periódicamente (grupo coordinado por un } \\
\text { moderador). }\end{array}$ & 19 & 97 & 208 & 324 & $7.9 \%$ & $18.5 \%$ & $59.6 \%$ & $29.2 \%$ \\
\hline $\begin{array}{l}\text { R22-Escuchar o participar en un programa de } \\
\text { Radio Anáhuac, en el que se comenten obras } \\
\text { literarias. }\end{array}$ & 34 & 98 & 166 & 298 & $14.2 \%$ & $18.7 \%$ & $47.6 \%$ & $26.8 \%$ \\
\hline $\begin{array}{l}\text { R20-Participar en un maratón o concurso de } \\
\text { lectura en voz alta. }\end{array}$ & 19 & 80 & 119 & 218 & $7.9 \%$ & $15.3 \%$ & $34.1 \%$ & $19.6 \%$ \\
\hline
\end{tabular}




\section{CONCLUSIONES}

Es aspiracional que los textos que lean los estudiantes universitarios, ya sean curriculares o extracurriculares, abonen de alguna manera en su formación integral. Por ello, se han de enfatizar no solo los textos de los que emana el saber de la ciencia o el saber pragmático, sino también el saber culto, el que apela a la condición humana, el que nos hace ser quienes somos, porque nos permite entendernos a nosotros mismos, y relacionarnos con los otros y con el mundo. La práctica de la lectura en la universidad, debe formar lectores críticos y autónomos capaces de cuestionarse, de aprender y de hacer vida la lectura.

Los resultados de la investigación presentan tres perfiles o niveles de lector literario: bajo, medio y alto, de acuerdo a la disposición de los estudiantes ante la literatura. Como se ha expuesto, conforme sube el perfil de nivel, incrementa el gusto, la importancia y la vivencia de la literatura, así como el interés por participar en actividades promotoras de la lectura de obras literarias.

Es importante que la universidad diseñe e implemente actividades acordes con estos perfiles, para seguir impulsando el desarrollo lector de los perfiles medio y alto, y de manera especial y prioritaria, atender y profundizar sobre las necesidades del perfil bajo, pues es donde se presenta el menor gusto por la lectura de obras literarias (al 92.1\% le gusta poco o nada).

Por lo anterior, no es de sorprender que, en este grupo, la gran mayoría (76.4\%) solo haya leído entre una y tres obras literarias el último año (sin que podamos precisar si fue por gusto o por obligación), y que los porcentajes de estudiantes que reconocen favorablemente la importancia de la literatura y la hacen vida, también sean los más bajos. Si bien en este perfil se identifica la menor proporción de estudiantes de la muestra (21.5\%), no obstante, esto es un reto para la institución, ya que el interés por participar en las diferentes actividades promotoras de la lectura, también es el más bajo. ¿A qué se debe esta baja disposición ante la lectura de obras literarias? Cabe plantearse un estudio complementario de corte cualitativo, para explorar las causas en los diferentes perfiles.

Por otra parte y considerando la muestra del estudio en general, es importante destacar que, en cuanto a la importancia de la literatura (Tabla 7), un mayor porcentaje de estudiantes en los tres perfiles reconoce la relacionada con la cultura, la condición humana, los saberes, las historias y experiencias que dan sentido a la propia existencia, de acuerdo a los reactivos: «R7-La literatura nos permite conocer y entender nuestra cultura y la cultura de otros pueblos [...]» $(80.6 \%)$; «R6-En los personajes de los libros, se ve reflejada la experiencia o la condición humana» (75.2\%), y «R9-La literatura me permite acceder a saberes, historias y experiencias de la humanidad (favorables y desfavorables), que al interpretarlas, cobran sentido para mi propia existencia» $(74.1 \%)$.

En contraparte, la importancia de la literatura que un menor porcentaje de estudiantes seleccionaron, especialmente en el perfil bajo, es la directamente relacionada con su poder formativo, de lo que dan cuenta los reactivos siguientes: «R8-Permite identificar en los personajes, modelos a seguir y anti modelos a evitar» (40.6\%); «R4-Es un medio de formación en valores» $(38.5 \%)$; «R3-Favorece el conocimiento de uno mismo, de los otros y del mundo» $(35.6 \%), y$ «R5-Leer obras literarias puede contribuir (entre otros aspectos) a que seamos mejores personas» $(35.1 \%)$.

Respecto a la frecuencia con la que hacen vida la literatura (Tabla 8), en los tres perfiles el mayor porcentaje reportó «Sentir empatía por las circunstancias de los personajes, ya 
sean favorables o desfavorables» (R12 - 52.7\%); «Identificar qué enseñanzas y valores son aplicables a su propia vida» (R13 - 47.3\%), e «Identificar qué aspectos de la historia o de las actitudes y acciones de los personajes se asemejan a la vida real» (R11 - 43.7\%). No obstante, identificar estas enseñanzas, valores, actitudes y acciones de los personajes, no conlleva directamente a ponerlos en práctica, como se puede ver en el bajo porcentaje del reactivo «Pones en práctica las enseñanzas de la obra literaria para mejorar algún aspecto de tu vida» (R14 - 29.4\%), especialmente en los perfiles bajo y medio. Este aspecto es crucial para que la obra literaria incida de manera más significativa en los estudiantes, y no se quede, como señala Argüelles (2017), en una exquisita trivialidad.

Asimismo, entre los porcentajes más bajos se identifica también la socialización de la lectura (R15-Compartes con otras personas las reflexiones o enseñanzas que te dejó la obra literaria), que es la manera de intercambiar aquello significativo que nos dejó una obra literaria y, por tanto, nos abre a la posibilidad de adquirir una apreciación más completa de la obra.

Por lo anterior, es necesario que las actividades promotoras de la lectura de obras literarias (Tabla 9), aborden de manera explícita la importancia de la literatura para la formación (más allá del ocio o pasatiempo), enfatizando que esta cobra mayor significado o sentido, cuando el texto se hace vida e incide en el desarrollo personal. Las actividades más propicias para ello son: incluir la lectura de obras literarias en algunas materias (R26); asistir a conferencias, foros o paneles de expertos donde se hable de obras literarias (R19); asistir a presentaciones de obras literarias por parte de los escritores (R18); asistir a cursos o talleres (R21) y formar parte de un club de lectura (R17), ya que en estas se podrían abordar las experiencias de humanización y deshumanización de los personajes, que tengan eco en la propia existencia y ello posibilite la acción transformadora de la literatura.

En cuanto a las actividades promotoras de la lectura en general, es contrastante el porcentaje de estudiantes en los diferentes perfiles a los que les gustaría participar de forma regular o mucho. Los perfiles bajo y medio, tienen porcentajes por debajo de $50 \%$ en todos los casos, en cambio, en el perfil alto, se alcanzan porcentajes por arriba de $50 \%$ en la mayoría de las actividades y hasta un $86 \%$. Al respecto, conviene explorar qué otros aspectos inciden, más allá del gusto o no por la lectura de obras literarias, en la participación de los estudiantes en actividades promotoras de la lectura. Como señala Astin (1984, p. 523), la institución compite con otras fuerzas por el tiempo del estudiante (familia, amigos, trabajo, etcétera), y convendría agregar a la lista otras tareas académicas y prácticas culturales que, quizá sean de mayor interés que la práctica de la lectura, especialmente en los perfiles bajo y medio, y para quienes esta actividad gusta poco o nada.

En suma, es importante considerar las preferencias de los estudiantes para enfocar los esfuerzos de promoción de la lectura, bajo una estrategia dirigida, y considerar su participación en la planeación de las actividades. Por ejemplo, seleccionar los días, horarios y espacios físicos que resulten más convenientes para ellos, e involucrarlos en la organización y promoción de las propuestas. Es especialmente relevante apoyarse en los estudiantes de perfil alto, ya que pueden ser agentes naturales para contagiar el gusto por la lectura que, de acuerdo a Argüelles (2017, p. 52), es la mejor forma de promoción. Si queremos atraer a los jóvenes de perfil bajo e impulsar al grupo de perfil medio, quién mejor que lectores asiduos y estratégicamente seleccionados, capaces de transmitir la pasión por la lectura y la importancia de la literatura para el desarrollo personal.

Por otra parte, a manera de criterios de acción para avanzar en un plan de fomento a la lectura, se sugiere: a) impulsar las actividades que ya ofrece la institución, asegurando una 
campaña de comunicación efectiva para llegar a los estudiantes, y determinar cuáles conviene mantener o reemplazar; b) de ser posible, favorecer las actividades de promoción que tuvieron un mayor porcentaje de aceptación entre los estudiantes de los tres perfiles, tal es el caso de: «R25-Asistir a ferias de libro para enterarte de novedades literarias, acudir a la presentación de un libro o adquirir libros»; «R23-Recibir material impreso o digital [...] con recomendaciones de obras literarias», y c) ampliar periódicamente la oferta de actividades, considerando los recursos institucionales y las preferencias de los estudiantes.

De esta forma, la presente investigación es una invitación y una propuesta de medición, para que las instituciones educativas conozcan el perfil lector literario de los estudiantes de nuevo ingreso, a fin de brindarles experiencias de fomento a la lectura acordes con sus intereses y necesidades. El instrumento podría ser utilizado bajo un esquema preprueba/posprueba, para medir si dichas experiencias han sido exitosas en la medida en que incrementan el gusto por la lectura de obras literarias, su importancia y la vivencia percibida de las mismas.

\section{REFERENCIAS}

Arendt, H. (2017). La condición humana. PAIDÓS.

Álzaga, Florinda (2001). La literatura más allá de la estética. Círculo: Revista de Cultura, Vol. XXX, 65-75.

Argüelles, J. D. (2017). ¿Qué leen los que no leen? El poder inmaterial de la lectura, la tradición literaria y el hábito de leer. OCEANO.

Astin, A. W. (1984). Student Involvement: A Developmental Theory for Higher Education. Journal of College Student Development, 5(40), 518-529.

Eco, U. (2017). Sobre algunas funciones de la literatura. Sobre literatura. Penguin Random House.

Fromm, E. (1980). Ética y Psicoanálisis. Fondo de Cultura Económica.

García, M. (2013). Kierkegaard y la comunicación indirecta. Algunos comentarios a La Alternativa. Tópicos. Revista de Filosofía, 5(1), 113-139. https:// doi.org/10.21555/top. $\underline{\mathrm{v} 5 \mathrm{i} 1.515}$

George, D. \& Mallery, P. (2003). SPSS for Windows step by step: A simple guide and reference. 11.0. Allyn \& Bacon.

Goodman, K. (2015). Sobre la lectura. PAIDÓS.

IBBY MÉXICO (2019). Segunda Encuesta Nacional sobre Consumo Digital y Lectura entre Jóvenes Mexicanos. https://www.ibbymexico.org.mx/wp-content/uploads/2019/12/ present-definitiva-Ejecutivo-LECTURA1901.pdf

Instituto Nacional de Estadística y Geografía (INEGI) (2020). Módulo sobre lectura (MOLEC). Principales resultados. Febrero 2020. https:/ / www.inegi.org.mx/contenidos/ programas $/ \mathrm{molec} / \mathrm{doc} /$ resultados molec feb20.pdf 
Larrosa, J. (2003). La experiencia de la lectura, Literatura, experiencia y formación. Fondo de Cultura Económica.

López Quintás, A. (1994). Cómo formarse en ética a través de la literatura: análisis estético de obras literarias. Rialp.

Manguel, A. (2014). El viajero, la torre y la larva. El lector como metáfora. Fondo de Cultura Económica.

Organización de las Naciones Unidas para la Educación, la Ciencia y la Cultura (UNESCO) (1982). Declaración de México sobre las Políticas Culturales. Conferencia mundial sobre las politicas culturales. https://culturalrights.net/descargas/ drets culturals400.pdf

Pérez, J. A. (1995). Filosofía y crítica de la cultura. Trotta.

Pérez, R. (2010). La Disposición de Ánimo (o de Espíritu) en Max Scheler: Elementos para la Orientación Filosófica. HASER. Revista Internacional de Filosofía Aplicada , 1, 67-89. https://idus.us.es/bitstream/handle/11441/58387/LA\%20DISPOSICI \% c3\% 93N\%20DE\% 20\%c3\%81NIMO \% 20\% 28O\%20DE\%20ESP\%c3\%8dRITU $\% 29 \%$ e2\%80\%9d $\% 20 \mathrm{EN} \% 20 \mathrm{MAX}$.pdf? sequence $=1 \&$ isAllowed $=\mathrm{y}$

Reyes, A. (1944). El deslinde. Fondo de Cultura Económica.

Reyes, A. (1997). Hermes o de la comunicación humana. La experiencia literaria. Obras Completas de Alfonso Reyes XI. Fondo de Cultura Económica.

Rivas, R. (2013). Erich Fromm: Bases para una antropología paradójica y una ética «negativa». EN-CLAVES del pensamiento, 7(14), 103-122. Recuperado 19-11-2021. http:/ / www.scielo.org.mx/scielo.php?script=sci arttext\&pid=S1870-879X2013000200005

Scheler, M. (1937). El saber y la cultura. Editorial Cultura.

Scheler, M. (2003). El puesto del hombre en el cosmos. Editorial Losada.

Sobrevilla, D. (1998). Filosofía de la Cultura. Trotta.

Steiner, G. (2003). Humanidad y capacidad literaria. Lenguaje y silencio. Gedisa.

Tolkien, J. R. R. (1994). Sobre los cuentos de hadas. Árbol y hoja y el poema Mitopoeia. Minotauro.

Torres, F. (2009). Involucramiento estudiantil del universitario mexicano y su relación con el desarrollo académico y personal. Tesis. Estado de México.

Vargas Llosa, M. (2000). Un mundo sin novelas. Letras libres. https://www.letraslibres. $\mathrm{com} / \mathrm{mexico} / \mathrm{un}-\mathrm{mundo}$-sin-novelas

Zaid, G. (1982). La feria del progreso. Taurus. 